\title{
Steels with High Temperature Carbides - New Possibilities for Semi-solid State Processing JIRKOVÁ Hana ${ }^{1, a}$, RUBEŠOVÁ Kateřina ${ }^{1, b}$, PILEČEK Vít ${ }^{1, c}$, BEHÚLOVÁ Mária ${ }^{2, d}$ ${ }^{1}$ University of West Bohemia, Research Centre of Forming Technology - FORTECH, Pilsen,
Czech Republic \\ ${ }^{2}$ Slovak University of Technology in Bratislava, Faculty of Materials Science and Technology in Trnava, Trnava, Slovakia

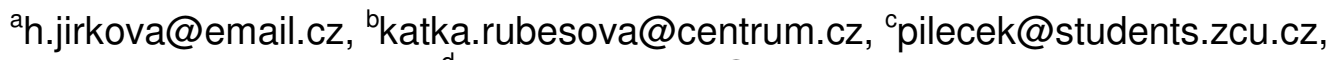 dmaria.behulova@stuba.sk
}

Keywords: semi-solid processing, powder metallurgy, mini-thixoforming, unconventional structures of tool steels.

\begin{abstract}
Semi-solid processing of steels is typically studied using high-alloy steels with higher carbon levels, as those offer a long freezing range which is favourable for conducting the process. The drawback to their application is their microstructure which typically consists of austenite grains embedded in ledeburitic network. This type of microstructure typically fails in brittle manner by fracturing along the interface of the hard network and ductile austenite grains. This is why a way was sought to altering or even inverting the configuration of the microstructure. Eventually, suitable steel chemistries were found which allow the inverted microstructure to be obtained. With regard to the high content of alloy additions, these steels have to be made by powder metallurgy methods.

Five different steels of this kind were selected for the experimental programme. All contained high amounts of alloying elements and a large fraction of carbides. Their carbon content was taken into account as well, ranging from 0.55 to $3.4 \%$. Differences between the steels consisted in the levels of major alloying elements, namely chromium, vanadium, molybdenum, tungsten and cobalt. After suitable process parameters were found, semi-solid processing was used to prepare demonstration products. The transition through semi-solid state transformed the ferritic matrix to austeniticmartensitic one, in which the high-stability carbides were retained. The resulting microstructures were of unconventional nature where carbide particles were embedded in tough metal matrix. Their configuration was thus inverted in contrast to the ones typically obtained by semi-solid processing of tool steels.
\end{abstract}

\section{Introduction}

Key advantages of processing steels by thixo-forming include simple forming procedures, the capability to make complex-shape products and to use the near net shape forming, as well as higher productivity [1]. Another benefit is the possibility to shape high-alloy difficult-to-form materials. Today, thixo-forming of steels focuses predominantly on tool steels of X210Cr12, 100Cr6, HP9/4/30 or M2 types [2-7]. The thixo-formed microstructure is typically made up of polyhedral austenite grains embedded in carbide-austenite network. It was found during mechanical testing that these structures typically fail by brittle fracture propagating along austenite grain boundaries. In response to that, research was undertaken to invert this microstructure configuration into one where the high-stability carbides would be retained and become embedded in austenitic or austeniticmartensitic matrix. One of the available options is to use steels alloyed with suitable carbide formers in order to obtain favourable distributed high-stability carbides $[8,9]$. 


\section{Experimental Programme}

Experimental material. Fiver powder steels were selected for the experiment (Table 1). Their carbon contents were in the interval of 0.55 to $3.4 \%$ and their main alloying additions included chromium, vanadium, tungsten, molybdenum and cobalt. The initial condition of the received stock was the annealed state. In order to explore the microstructure evolution in CPM 15V, CPM S30V and K190 steels, the effects of vanadium and chromium were mapped first. In the REX 121 steel, the influence of tungsten, molybdenum and cobalt were studied as well. The CPM 1V steel was used as a reference material, mainly due to the low contents of carbon and other alloying elements.

Table 1: Chemical compositions of steels employed in the experiment [wt. \%]

\begin{tabular}{|c|c|c|c|c|c|c|c|c|c|c|c|}
\hline & $\mathrm{C}$ & $\mathrm{Cr}$ & $\mathrm{Mn}$ & $\mathrm{Mo}$ & $\mathrm{V}$ & $\mathrm{W}$ & $\mathrm{Co}$ & $\mathrm{Si}$ & $\begin{array}{c}\mathrm{T}_{\mathrm{S}} \\
{\left[{ }^{\circ} \mathrm{C}\right]}\end{array}$ & $\begin{array}{c}\mathrm{T}_{\mathrm{L}} \\
{\left[{ }^{\circ} \mathrm{C}\right]}\end{array}$ & $\begin{array}{c}\mathrm{T}_{\mathrm{L}}-\mathrm{T}_{\mathrm{S}} \\
{\left[{ }^{\circ} \mathrm{C}\right]}\end{array}$ \\
\hline CPM 15V & 3.40 & 5.25 & 0.50 & 1.30 & 14.5 & - & - & 0.90 & 1300 & 1320 & 20 \\
\hline CPM S 30V & 1.45 & 14 & - & 2 & 4 & - & - & - & 1230 & 1370 & 140 \\
\hline K190 & 2.3 & 12.5 & 0.4 & 1.1 & 4 & - & - & 0.1 & 1235 & 1340 & 105 \\
\hline REX 121 & 3.42 & 3.99 & 0.51 & 5.21 & 9.81 & 9.75 & 8.71 & - & 1190 & 1270 & 80 \\
\hline CPM 1V & 0.55 & 4.55 & 0.50 & 2.75 & 1.00 & 2.15 & - & - & 1345 & 1470 & 125 \\
\hline
\end{tabular}

Mini-thixoforming. Semi-solid processing was performed in a special-designed minithixoforming die [4] (Fig. 1). Thanks to the replaceable shaped die insert, products of various shapes can be made [9]. The feedstocks with a cylindrical body of $48 \mathrm{~mm}$ in length and $6 \mathrm{~mm}$ in diameter had cone frustum ends to allow clamping between copper electrodes. The pieces were heated in the die cavity by combined electrical induction and resistance methods.

Materials Characterization. Preliminary

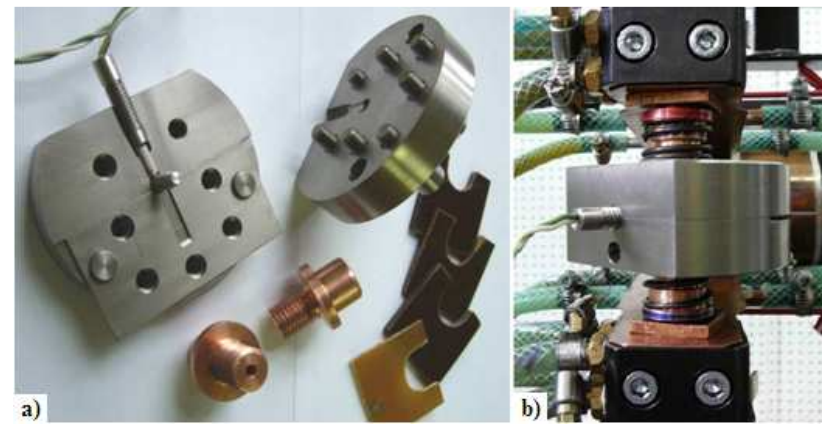

Fig. 1: Die for semi-solid forming: a) dismantled die with accessories, b) die clamped in thermomechanical simulator schedules for the steels were developed with the aid of calculation with JMatPro software [12]. With CPM 15V and CPM S30V steels, the liquidus and solidus temperatures were verified by means of DTA. Volume fractions of microstructure constituents were measured by means of quantitative $\mathrm{X}$-ray diffraction analysis using a diffractometer with a Co-K $\alpha$ source. The microstructures were revealed using V2A etchant (100 ml water, $100 \mathrm{ml}$ hydrochloric acid, $10 \mathrm{ml}$ nitric acid). Local chemical composition was measured by means of EDS.

\section{Results and Discussion}

Characterization of Input Material. The initial microstructure of all steels in question consisted of ferritic matrix and carbides. Besides chemical composition, the differences between carbides were in their shapes and sizes (Table 2, Fig. 2).

In the CPM15V steel, the initial microstructure comprised ferritic matrix and mixed globular vanadium and chromium carbides, as confirmed by the EDS analysis (Fig. 2). The ferritic matrix was enriched with silicon and manganese. The carbide size was approximately $3 \mu \mathrm{m}$. X-ray diffraction analysis revealed $18 \% \quad \mathrm{~V}_{8} \mathrm{C}_{7}$ vanadium carbides and $10 \% \quad \mathrm{M}_{23} \mathrm{C}_{6}$-type chromium carbides in the material. 
CPM S30V contained mixed carbides of both types as well (Fig. 2, Table 2). The light-coloured carbides with higher chromium content did not form isolated globular particles but rather clusters of particles. In most cases, they were chromium carbides of the $\mathrm{Cr}_{23} \mathrm{C}_{6}$ type.

In the K190 steel, very coarse sharp-edged chromium carbides were found. They were identified as the $\mathrm{Cr}_{23} \mathrm{M}_{6}$ type.

In the REX 121 steel, the initial microstructure consisted of ferritic matrix with $40 \%$ carbides which showed bimodal size distribution (Fig. 2). The exact distribution of chemical elements was mapped using EDAX detector in the Magellan microscope [13, 14]. The larger carbides, with the mean size of $3 \mu \mathrm{m}$, contained mainly vanadium, tungsten and molybdenum. The smaller carbides with sizes below $1 \mu \mathrm{m}$ consisted primarily of chromium. It was also found that the ferritic matrix is enriched with cobalt. This steel showed the highest hardness: 407 HV10.

The finest carbides of approx. $1 \mu \mathrm{m}$ were found in the CPM 1V steel (Fig. 2).

Table 2: Microstructure characteristics before and after mini-thixoforming

\begin{tabular}{|c|c|c|c|c|c|c|c|c|}
\hline & \multicolumn{4}{|c|}{ Initial condition } & \multicolumn{4}{c|}{ After mini-thixoforming } \\
\hline & $\begin{array}{c}\text { Vc } \\
{[\%]}\end{array}$ & $\begin{array}{c}\text { Size of } \\
\text { carbide [\%] }\end{array}$ & $\begin{array}{c}\text { V } \alpha \\
{[\%]}\end{array}$ & $\begin{array}{c}\text { HV10 } \\
{[-]}\end{array}$ & $\begin{array}{c}\text { Vc } \\
{[\%]}\end{array}$ & $\begin{array}{c}\text { V } \gamma \\
{[\%]}\end{array}$ & $\begin{array}{c}\text { V } \alpha \\
{[\%]}\end{array}$ & $\begin{array}{c}\text { HV10 } \\
{[-]}\end{array}$ \\
\hline CPM 15V & 28 & 3 & 72 & 292 & 21 & 50 & 29 & 657 \\
\hline CPM S 30V & 31 & $1-5$ & 70 & 310 & 16 & 70 & 14 & 468 \\
\hline K190 & 30 & $1-10$ & 70 & 232 & 23 & 59 & 18 & 543 \\
\hline REX121 & 40 & $1-3$ & 60 & 407 & 34 & 46 & 20 & 830 \\
\hline CPM1V & - & 1 & - & 212 & - & - & - & 863 \\
\hline
\end{tabular}
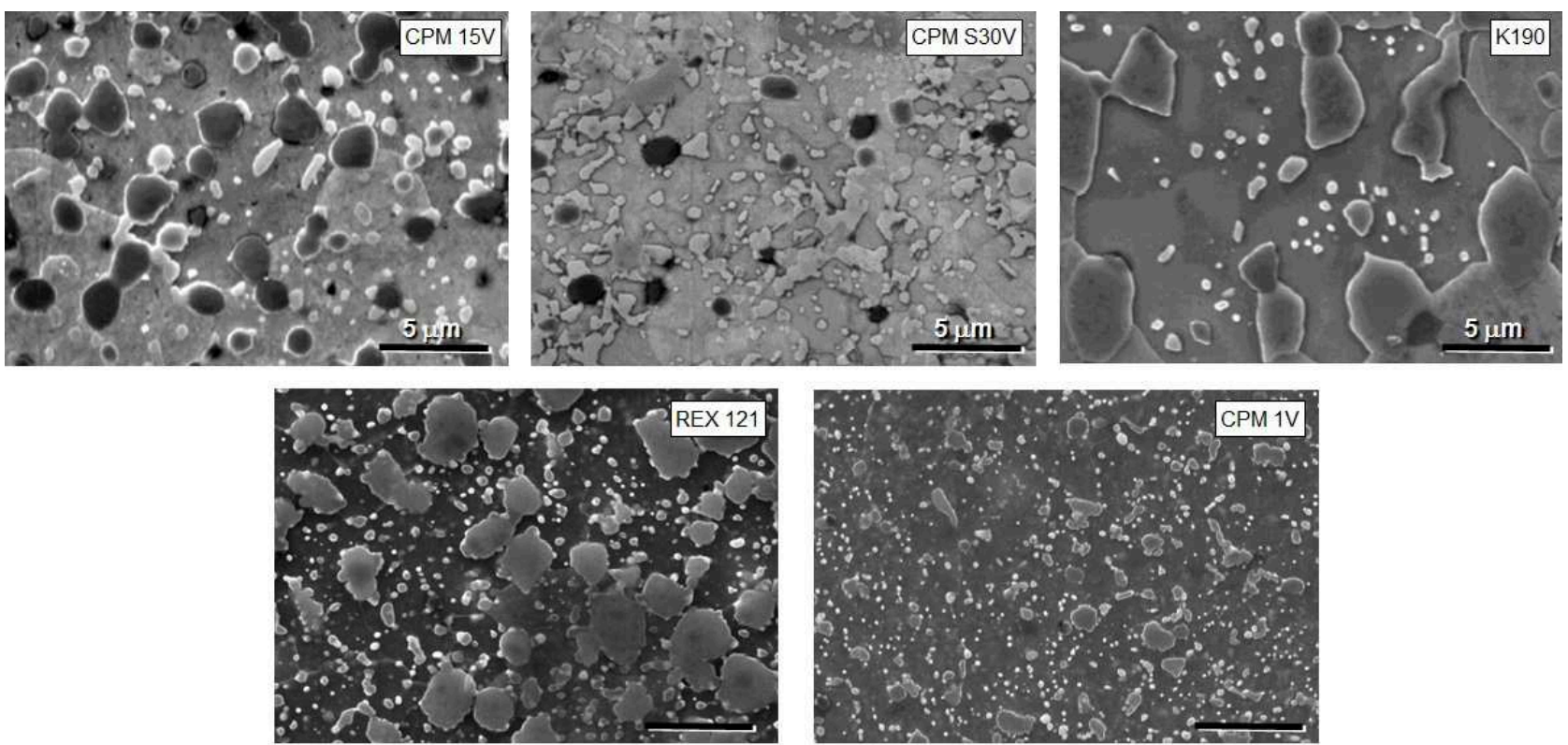

Fig. 2: Initial microstructures of steels prior to semi-solid processing

Identification of Mini-Thixoforming Processing Parameters. The first version of the set of processing parameters was developed on the basis of calculation in JMatPro software (Table 2, Fig. 3). The shortest freezing range was found in the CPM $15 \mathrm{~V}$ steel: a mere $20{ }^{\circ} \mathrm{C}$ (Table 1). By contrast, the widest interval was found in the CPM S30V steel. Another technical difficulty with these steels is the rapid increase in liquid fraction with the heating temperature (Fig. 3).

In addition to the JMatPro calculation, the melting temperature was also determined using DTA. With the CPM $15 \mathrm{~V}$ steel, a sample of $35.07 \mathrm{mg}$ weight was used. The sample was heated to $1425^{\circ} \mathrm{C}$ at the rate of $10 \mathrm{~K} / \mathrm{min}$. The temperature of the onset of melting was $1281{ }^{\circ} \mathrm{C}$. A majority of the material became molten at $1345^{\circ} \mathrm{C}$. The melting temperature found by DTA analysis matches the result of the JMatPro calculation. In this case, the difference was no more than $9{ }^{\circ} \mathrm{C}$. 
With the CPM S30V steel, a sample of $46.230 \mathrm{mg}$ weight was used. Since the results of the JMatPro calculation indicated the liquidus temperature may be higher, the heating temperature was set at $1460{ }^{\circ} \mathrm{C}$; with the heating rate of $10 \mathrm{~K} / \mathrm{min}$. The solidus temperature was found to be $1243{ }^{\circ} \mathrm{C}$. In this steel, on the other hand, the temperature found by direct measurement was higher than that determined by means of the software. Consequently, it was necessary to optimise the heating and deformation temperature in the first steps of the experimental programme.

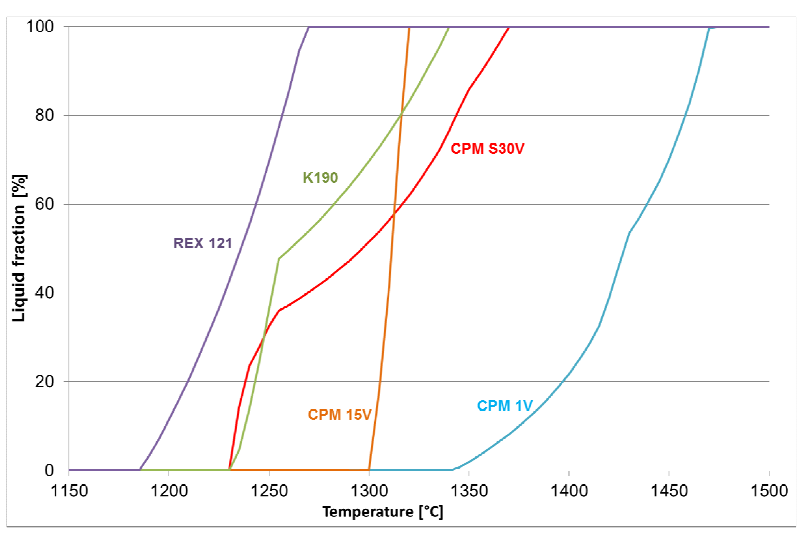

Fig. 3: Dependence of liquid fraction on temperature in individual experimental steels

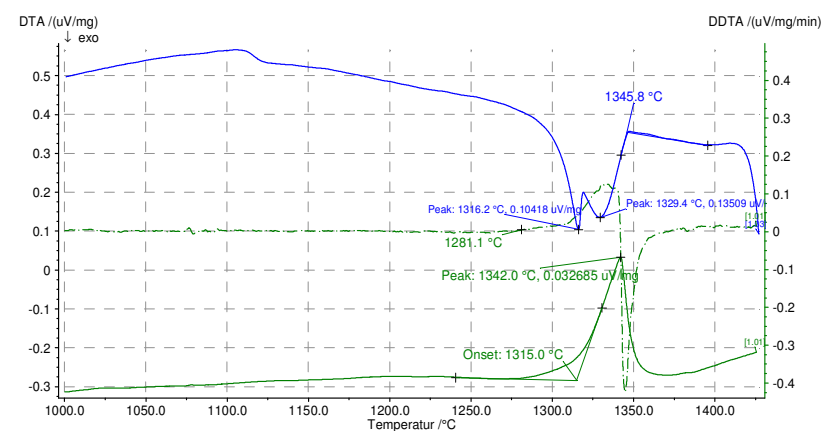

Fig. 4: DTA analysis of the CPM 15V material

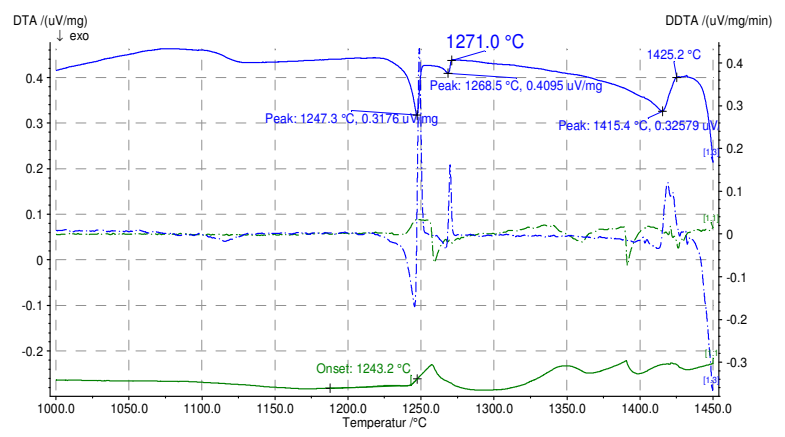

Fig. 5: DTA analysis of the CPM S30V material

Semi-Solid Processing. Processing parameters were sought for complete filling of the mould cavity in the form of a straight groove with the cross-section of $1.9 \times 5 \mathrm{~mm}$ and a $20 \mathrm{~mm}$ length. The objective was to achieve complete filling of the mould, including all features, and attaining highquality defect-free product surface. Heating took $56 \mathrm{~s}$ and forming was performed using a force of $7 \mathrm{kN}$.

With the CPM $15 \mathrm{~V}$ steel, the first heating temperature to be tested was $1300{ }^{\circ} \mathrm{C}$. At this temperature, the mould became only partially filled. Increasing the forming force proved ineffective and even forced the liquid metal to flow over the surface of the workpiece. It became apparent that the forming temperature should be changed. Reducing the temperature to $1270{ }^{\circ} \mathrm{C}$ was found to be adequate. At this processing temperature, the mould cavity was filled completely.

Based on calculations and the prior experience with processing the CPM $15 \mathrm{~V}$ steel, the first mini-thixoforming trial on the CPM S30V steel was performed at the temperature of $1280{ }^{\circ} \mathrm{C}$. Part of the metal escaped the mould and the surface of the product showed minute defects. The temperature was then reduced by $10{ }^{\circ} \mathrm{C}$ to $1270{ }^{\circ} \mathrm{C}$. At this forming temperature, the groove-shaped mould was filled completely. The resulting surface quality of the product was excellent. For the sake of completeness, the temperature for the next experiment in the programme was reduced by another $10{ }^{\circ} \mathrm{C}$, i.e. to $1260{ }^{\circ} \mathrm{C}$. In this case, however, the material ceased to be able to fill the mould cavity and the product showed surface defects.

For the K190 steel, the temperature of $1260{ }^{\circ} \mathrm{C}$ was used (Fig. 6). The process did not lead to the required product shape. As indicated by the results, the heating temperature was too high. The liquid metal even entered the narrow parting plane gap in the mould. The fact that the temperature was too high was also confirmed by metallographic observation, as the resulting microstructure contained predominantly dendrites. The temperature was reduced in $5^{\circ} \mathrm{C}$ steps to $1240^{\circ} \mathrm{C}$ (Fig. 6). The metal then filled the mould cavity completely. The length of the product was $16 \mathrm{~mm}$. Its surface was free of any visible defects. 
As the REX 121 steel had the lowest liquidus temperature due to its chemistry, its first forming trial involved a lower temperature than the other cases: $1215^{\circ} \mathrm{C}$. At this temperature, however, the liquid fraction was insufficient for achieving the required fluidity and thixotropic behaviour of the material. By raising the heating temperature in steps of $5^{\circ} \mathrm{C}$, the entire mould cavity was filled eventually and a product with the desired surface quality was obtained. The mould cavity with a cross-section of $1.9 \times 5 \mathrm{~mm}$ and a length of $20 \mathrm{~mm}$ was filled completely at the temperature of $1235^{\circ} \mathrm{C}$. In this case, the difference between the calculated and the actual optimum forming temperature was $20^{\circ} \mathrm{C}$.
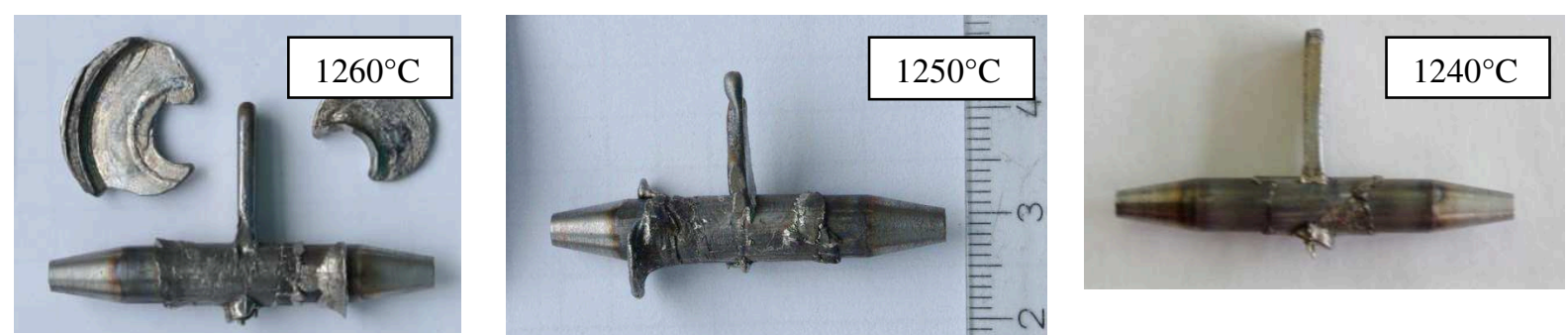

Fig. 6: Stepwise reduction in the heating temperature during optimization of mini-thixoforming parameters for the K190 steel

The highest heating temperatures were used with the CPM $1 \mathrm{~V}$ steel. Its melting interval began at $1345{ }^{\circ} \mathrm{C}$. The first temperature tried was $1385^{\circ} \mathrm{C}$, at which the material was expected to contain $15 \%$ liquid fraction, according to JMatPro calculations. The heating temperature was raised in steps to $1400{ }^{\circ} \mathrm{C}$ and $1410{ }^{\circ} \mathrm{C}$.
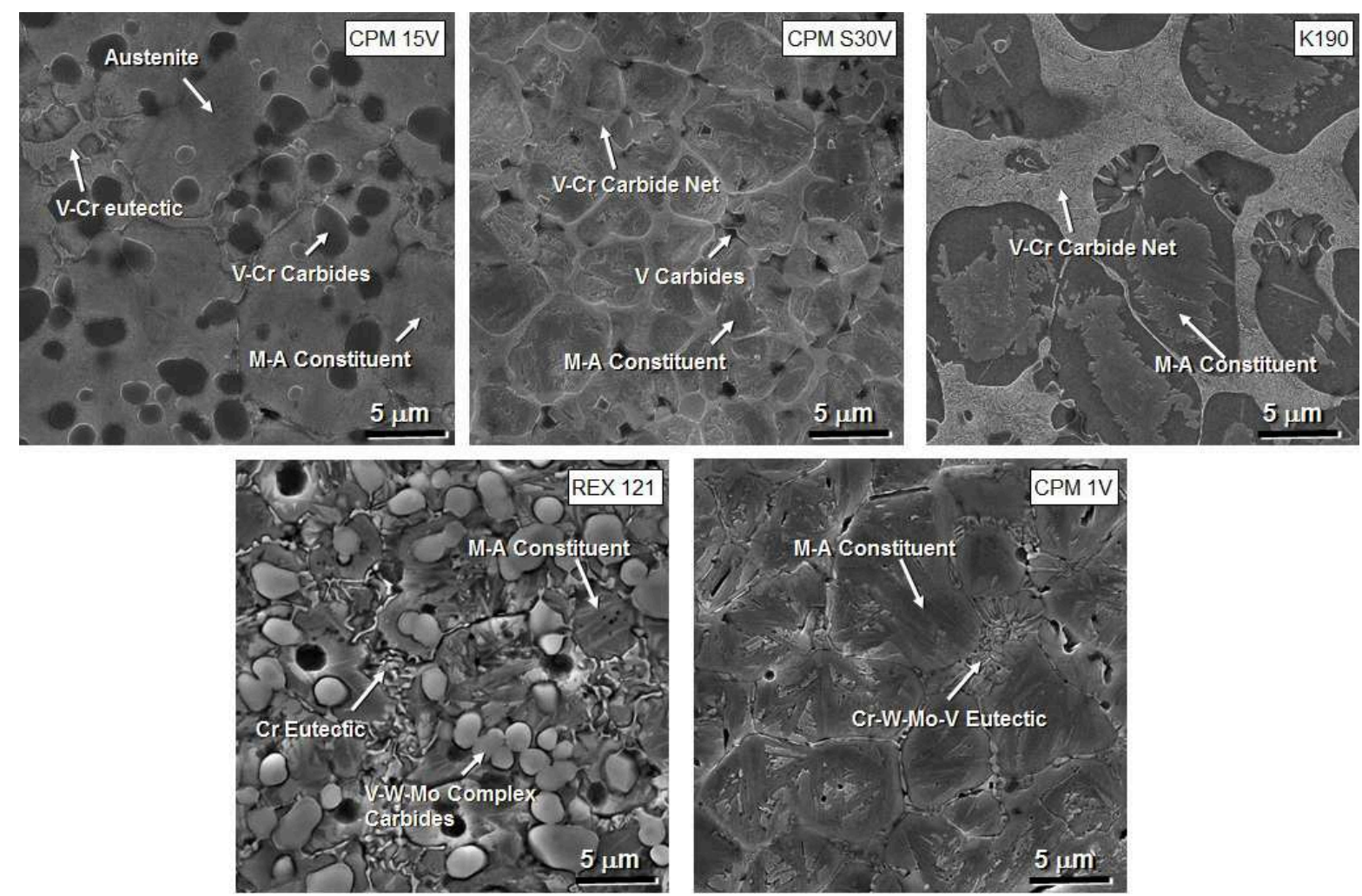

Fig. 7: Micrographs of semi-solid processed steels

Microstructure Characterization. The transition through the semi-solid state transformed the matrix of the CPM 15V steel substantially (Fig. 7). As expected, the resulting matrix consisted of austenite, in which martensite needles were found. The fractions of austenite and martensite were 50 and 20 per cent, respectively. As the high-stability $\mathrm{V}_{8} \mathrm{C}_{7}$ carbides were neither melted nor dissolved in the process, they remained in the material in their globular form. With this matrix, a high level of hardness was achieved, up to 657 HV10. Carbides with higher proportion of 
chromium dissolved during the thermal exposure and formed a small volume fraction of a eutectic on cooling.

Different types of microstructure were obtained in CPM S30V and K190 steels. Owing to their lower vanadium content, as opposed to the CPM $15 \mathrm{~V}$ steel, and the resulting lower proportion of high-stability carbides, most carbides dissolved in the solid solution. During rapid solidification in the mould cavity, carbide network formed along austenite grain boundaries. Considerable proportion of martensite was detected within austenite regions, the so-called M-A constituent, in particular in the K190 steel.

The chemistry of the CPM REX 121 steel contributed to the complex globular V-W-Mo carbides being retained (Fig. 7). The primary chromium carbides with the size below $1 \mu \mathrm{m}$ became partially melted and then re-precipitated in the form a eutectic along austenite grain boundaries. Semi-solid processing led to the hardness of $830 \mathrm{HV} 10$.

The largest increase in hardness was found in the CPM 1V steel which had the lowest carbon content of $0.56 \%$. While the as-received soft-annealed material had the hardness of $212 \mathrm{HV} 10$, the mini-thixoformed part showed $863 \mathrm{HV} 10$. Its microstructure consisted of austenite grains with a high proportion of the M-A constituent embedded the network of chromium carbides enriched with molybdenum and tungsten. Star-like eutectic formed locally (Fig. 7).

\section{Summary}

The aim of the experiment was to create a new inverted type of microstructure in steels by means of semi-solid processing. The character of the new microstructure was to be substantially different from the one routinely obtained by thixo-forming of high-alloy steels. The ordinary microstructure typically consists of polyhedral austenite grains with good plasticity properties embedded in brittle carbide network. Such a configuration with a limited range of mechanical properties typically leads to brittle failure under high loads. If the configuration were inverted, with brittle carbides embedded in strong but tough matrix, the mechanical properties of the material could be improved. With this goal, a suitable chemistry was sought which would allow the carbide network along austenite grain boundaries to be eliminated. In the experimental steels chosen, the high-stability carbides resisted dissolution. Consequently, they provided the frame for the inverted microstructure, as they were typically located in austenitic-martensitic matrix. Their morphology and sizes were dictated by the contents of alloying elements. The outcome confirmed the hypothesis that for this type of microstructure to develop, alloying elements which form appropriate types of carbides must be used. These include, in particular, vanadium, tungsten, cobalt and molybdenum. Where larger amounts of complex chromium carbides were present, as in the CPM S30V and K190 steels, they dissolved and re-precipitated on cooling in the typical form of the carbide network surrounding austenite grains with the M-A constituent. Adequate processing parameters, including the forming temperature, were found for all steels in question, allowing the mould cavity to be filled completely, including all its features, and providing products with inverted microstructure and high surface quality.

Acknowledgements. This paper includes results achieved in the project GA ČR P107/12/2600 Effect of Forming in Semi-Solid State on Evolution of Microstructure of Powder Metallurgy Steels. The project is subsidised from specific funds of the Czech state budget for research and development. And the research has been also supported by the Scientific Grant Agency of the Slovak Republic (VEGA) within the project No. 1/1041/11 and the project ITMS 26220120048 under the Research \& Development Operational Programme funded by the ERDF. 


\section{References}

[1] P. Cezard, T. Sourmail, Thixoforming of Steel: A State of the Art from an Industrial Point of View, Solid State Phnenomena 141-143 (2008) 25-33.

[2] B. Amin-Ahmadi, H. Aashuri, Semi-solid Structure for M2 High Speed Steel Prepared by Cooling Slope, Journal of Materials Processing Technology 210 (2010) 1632-1635.

[3] H. V. Atkinson, Alloys for Semi-Solid Processing, Solid State Phenomena 192-193 (2013) 1627.

[4] B. Masek, et al., Structure of Miniature Components from Steel Produced by Forming in Semisolid State, Transactions of Nonferrous Metals Society of China 20 (2010) 1037-1041.

[5] D. I. Uhlenhout, J. Kradolfer, W. Püttgen, J. F. Löffler, P. J. Uggowitzer, Structure and properties of a hypoeutectic chromium steel processed in the semi-solid state, Acta Materialia 54 (2006) 2727-2734.

[6] W. Püttgen, B. Hallstedt, W. Bleck, P. J. Uggowitzer, On the microstructure formation in chromium steels rapidly cooled from the semi-solid state, Acta Materialia 55 (2007) 1033-1042.

[7] M. Z. Omar, E.J. Palmiere, A.A. Howe, H.V. Atkinson, P. Kapranos, Thixoforming of a high performance HP9/4/30 steel, Materials Science and Engineering A 395 (2005) 53-61.

[8] I. Sen, H. Jirkova, B. Masek, M. Böhme, M.F.-X. Wagner, Microstructure and mechanical behavior of a mini-thixoformed tool steel, Metall. Mater. Trans. A, 43 (2012), 3034-3038.

[9] H. Jirkova, et al., Mini-thixoforming of a steel produced by powder metallurgy, Solid State Phenom. 192-193 (2013), 500-505.

[10] D. Aišman, H. Jirková, M. Behulová, B. Mašek, Influence of Cavity Shape and Entry Hole on Minithixoforming, METAL 2011, Ostrava : TANGER, 2011, 210-215, ISBN: 978-80-87294-24-6.

[11] Mašek, B.; Aišman, D.; Jirková, H.; Wurster, S., Micro-Compression Test of Thixoformed Austenite in: Solid State Phenomena 192-193 (2013), 215-218.

[12] JMatPro - Practical Software for materials Properties, Version 6.1, $<$ http://www.sentesoftware.co.uk>, (accessed 05/2013).

[13] D. Aišman, K. Rubešová, Š. Mikmeková, Mini-thixoforming of High-Alloyed CPM REX 121 Steel, Advanced Materials Research 887-888 (2014) 1156-1160. 